\title{
PRESENCIA NATURAL DE ARSENICO EN AGUAS DE POZOS PROFUNDOS Y SU REMOCIÓN USANDO UN PROTOTIPO PILOTO BASADO EN COLECTORES SOLARES DE BAJO COSTO
}

\author{
Ramiro Escalera Vásquez, Mauricio Ormachea, Omar Ormachea y Miguel Heredia
}

\section{RESUMEN}

Se ha realizado un relevamiento de la calidad físico-química y presencia de arsénico en aguas de pozos con profundidad mayor a $50 \mathrm{~m}$, ubicados en la zona periurbana oeste de la ciudad de Cochabamba, mediante muestreos llevados a cabo durante dos periodos diferentes (húmedo y seco). Por otra parte, se ejecutó un estudio de desempeño de una planta piloto de tratamiento para la remoción de arsénico (As) basado en la aplicación de colectores solares de bajo costo, construidos con materiales reciclables de fácil accesibilidad.

Las aguas subterráneas son del tipo calcio-bicarbonato $\left(\mathrm{Ca}-\mathrm{HCO}_{3}\right)$ por su predominancia sobre otros cationes y aniones, son ligeramente alcalinas ( $\mathrm{pH} 7,4-8,3$ ) y sus concentraciones de hierro (Fe (II) y manganeso (Mn (II) disueltos son relativamente altas, variando entre $<0,1$ y $2,1 \mathrm{mg} / \mathrm{L}$ y $<0,1$ y $1,2 \mathrm{mg} / \mathrm{L}$, respectivamente. Son moderadamente reductoras, con potencial óxido-reducción (ORP) entre -12,5 y $69 \mathrm{mV}$. Existe una significativa presencia natural de As. Cerca de la mitad de las muestras presentan valores superiores al valor requerido por la Norma Boliviana de Agua Potable (NB 512) de $10 \mu \mathrm{g} / \mathrm{L}$. En el periodo seco (8 meses) cerca del $40 \%$ de las muestras la superan en más de 10 veces. El desempeño del sistema de tratamiento piloto, mediante el proceso de Remoción Asistida por Oxidación Solar (RAOS), fue satisfactorio incluso en días nublados con remociones mayores al 80\%, logrando reducir la concentración de As hasta valores muy por debajo de lo requerido en la Norma Boliviana de agua potable. Existe una remoción muy significativa de As (cerca del 75\%) en la trayectoria que va desde la boca de pozo hasta la entrada al sistema de tratamiento. La remoción puede explicarse por la presencia de incrustaciones de óxidos de hierro (III) y manganeso (IV) depositadas en la superficie de la línea de distribución, que incluye tuberías y tanques de almacenamiento, que pueden adsorber los arseniatos formados por la aireación en el trayecto. La aireación con aspersores comerciales domésticos puede lograr efectivamente la oxidación de arsenitos a arseniatos.

Palabras Clave: Arsénico, Cochabamba, Remoción de Arsénico Asistida por Oxidación Solar (RAOS). 